\title{
The multiple dimensions of managerial networking
}

\author{
René Torenvlied, Utrecht University / University of Groningen \\ Agnes Akkerman, Radboud University Nijmegen / Utrecht University \\ Kenneth J. Meier, Texas A\&M University / Cardiff University \\ Laurence J. O’Toole, Jr., University of Georgia
}

Paper prepared for the PMRC Asia Conference

Hong Kong, August 14-16, 2010

\begin{abstract}
The present paper shows that managerial networking is not a one-dimensional phenomenon, as is commonly assumed in the literature on network management, but has several dimensions. Because public managers make selective investments in their network contacts, multiple dimensions of network activity emerge. Mokken-scale analysis on the network ties of Texas school district superintendents for the years $2002(n=639)$ and $2005(n=683$ shows the existence of three stable and homogeneous networking activity scales, which aim at generating: (1) political support, (2) bureaucratic coping, and (3) coproduction.. To illustrate the potential contribution of cumulative scaling techniques for network management research, we compare the results of this technique with those of the more commonly used factor analysis in an analysis of managerial network activity and school district performance. The paper concludes with a discussion of the implications of results for a deeper understanding of managerial networking and a better explanation for different indicators of agency performance.
\end{abstract}

Key words: managerial networking, Mokken scale analysis, factor analysis, public management.

Word count: 8,021 


\section{The multiple dimensions of managerial networking}

\section{Introduction}

Networks and managerial networking matter for organizational performance. Research shows that characteristics of networks and the externally-oriented networking behavior of managers in the public sector affect the performance of agencies (for instance, Agranoff and McGuire 2003; Bardach 1998; Hite et al. 2005; O’Toole and Meier 1999; O’Toole 1997; Rethemeyer 2007; Schalk et. al 2010). In the private sector, the network activity of firms is reported to positively affect survival rates, economic output, and innovativeness (Powell and Smith-Doerr 1994; Zaheer, McEvily, and Perrone 1998). Networks enhance the use of new organizational practices, technologies, and management innovations (Brass et al. 2004; Collins and Clark 2003; Kraatz 1998; Mizruchi 1994; Stuart and Podolny 1999; Tsai 2001). Networks with particular characteristics, such as the presence of a central coordinating organization, perform better than other networks (Provan and Milward 1995; Provan and Kenis 2008; Akkerman et al. 2009).

If networks matter, the management of network relations becomes a key variable for understanding agency performance. An early empirical study in this field is the analysis of the diverse network contacts of agencies for labor market training in Sweden and Germany (Hanf, Hjern and Porter 1978). Other studies of managerial networking focus on the activities of top managers and on the strength of their contacts with specific types of external actors and organizations—-such as suppliers, stakeholders, clients, alliance partners, regulatory agencies, or political institutions. In their study of urban schools, Leana and Pil (2006) refer to such managerial networks as the "external" social capital of these schools. In their various studies of Texas school districts, Meier and O'Toole (2003) and O'Toole and Meier (1999; 2004) argue that managerial networking outward into the interdependent environment taps opportunities to exploit resources in the district's environment and buffer environmental shocks, such as political, economic, and technical demands (O’Toole 1997).

Although there is convincing evidence that managerial networking affects agency performance, the evidence still remains at a very general level. Studies of Texas school district superintendents consistently show the existence of only one common "network activity" factor (e.g. Meier and O’Toole 2003: 692; O'Toole and Meier 2004: 479). A study of school principals only uses the time spent by these principals to maintain contacts with external organizations as an indicator for managerial networking activity (Leana and Pil 2006). A study of directors of colleges for nursing studies shows that there is one cumulative 
scale of "network ambition," with the most ambitious director maintaining strong relations with many different external organizations (Akkerman and Torenvlied 2010). All these studies imply that managers-apparently_do not differentiate between types of external organizations when they decide to allocate their scarce time and resources. This implies that when managers are actively networking, they direct their activities towards a diverse range of external actors and organizations.

The approach taken thus far in the empirical research literature, in other words, frames the likely importance of managerial networking for performance in terms of the multiple functions that, it is presumed, public managers must engage as they interact with others outside their core agency-tapping various kinds of opportunities and resources in their environment, buffering their organization from negative shocks—but the limitations of much large- $n$ research have typically precluded knowing much about what managers actually do as they operate in their organization's interdependent environment. ${ }^{1}$

This focus on only one, general dimension of managerial networking activity reveals an important link between managerial behavior and organizational performance; at the same time, however, it obscures a great deal of information. More progress in research on managerial networking could occur if we can identify a way to explore different dimensions of managerial action as managers seek support from the agency's environment-and can do so without reducing the large number of cases being analyzed. If successful, such an effort would enable researchers to classify managers by their approach to networking and also to study the implications of different dimensions of network activity on specific indicators of agency performance. The first aim of the present paper is to propose a simple, explanatory model that provides a foundation for the multidimensional nature of managerial networking. The model assumes that managers have limited time and resources available for maintaining relations with actors and organizations in an agency's environment. Because these relations involve transaction costs, managers will be selective in their choices regarding: (a) the specific contacts in which to invest, and (b) how much to invest in each contact. Managers should maintain stronger relations with external organizations that they perceive will generate greater benefits to the agency.

\footnotetext{
${ }^{1}$ O'Toole and Meier (1999) model the hypothesized influence of management on performance in terms of two broad aspects of external activity: efforts to exploit opportunities and resources, on the one hand, and efforts to protect or buffer, on the other. They also hypothesize functional forms for these relationships. For the most part, however, they measure the externally oriented behavioral interactions of managers in a fashion that precludes direct information about the different possible activities or functions that are involved as they interact with others.
} 
From this simple model, we derive two hypotheses. The first is that multiple dimensions of networking activity exist, and that these correlate with different types of support from external organizations. Which substantive dimensions of public managers' network activity can be found should depend on the type of agency under study, as well as institutional, cultural, and contextual factors. The second hypothesis is that we expect differences across organizations that are in the core agency's environment in the degree to which managers in the core agency invest in interactions with the external units. Relations with particular organizations may require more effort from the manager or have higher priority. If such differences in investment exist across external organizations, the dimensions are represented by cumulative scales rather than by a common factor. We discuss this methodological issue in more detail below.

The second aim of the present paper is to illustrate the advances of cumulative scaling techniques by testing our hypotheses on the Texas school district public management studies ${ }^{2}$ of Meier and O'Toole (2003) and O'Toole and Meier (1999). We use a non-parametric cumulative scaling technique-Mokken scale analysis-to check which homogeneous cumulative scales of managerial networking can be identified. Mokken scale analysis is based on item response theory, which enables us to separately estimate the difficulty of contacting different types of external organizations and also the time and effort spent by superintendents on particular dimensions of network activity. A factor analysis can produce biased results when a cumulative scale applies (Van Schuur 2003). Mokken scale analysis is not yet widely used in policy analysis or public management research, with a few notable exceptions. For example, Jacoby $(1994 ; 2000)$ uses this technique to find different dimensions of social support for public spending. Schneider, Jacoby, and Coggburn (1997) use Mokken scale analysis to find dimensions of bureaucratic decisions in state Medicaid programs.

We check and test for the existence of cumulative scales in the networking data from the Texas school district studies of Meier and O'Toole for two waves: 2002 and 2005. Their studies contain data on the frequency and initiative in contacts between superintendents and external actors and organizations, such as: parent groups, local business leaders, teacher associations, Federal officers, the Texas Education Authority, and local politicians. The superintendents were asked a range of questions about goals, administrative style, allocation of time, and —of particular importance for present purposes — externally oriented interactions with a range of outside parties. In effect, the top managers were asked with whom they

\footnotetext{
${ }^{2}$ The Texas school district data are available from Kenneth J. Meier and Laurence J. O’Toole, Jr. We are grateful for their having made the data available to us.
} 
interact externally, and how often—on a six-point scale ranging from "never" to "daily." These responses on frequency of contacts provide data on the intensity of the various relations. Response rate for the approximately 1000 superintendents in each year ranged from 55 to 67 percent, and the districts represented in the samples are quite representative of the full set. All these school districts are charged with educating students, but otherwise the districts are quite heterogeneous in terms of size, racial and ethnic characteristics of district clientele, wealth, and other characteristics.

Below, we introduce our simple model of managerial network activity and discuss our hypotheses. We introduce the context of the Texas school districts. Subsequently, we describe the study design and measurement of the network contacts between school district superintendents and external organizations. We give a brief introduction to Mokken scale analysis as an alternative to factor analysis. In the results section, we present three homogeneous cumulative scales of network activity that are present in the data. We provide an interpretation for these scales. We demonstrate the potential for cumulative scaling techniques by comparing the effects of networking activity in the dimensions-found in the Mokken scale analysis-on school district performance with the effects of the factor scores retrieved from the more commonly used standard factor analysis. The paper concludes with a discussion of implications for public management theory, the relevance of cumulative scaling techniques for public administration research, and a sketch of other promising avenues for future research.

\section{Investments in dimensions of managerial network activity}

To understand the networking activities of public managers, we must specify the mechanisms that drive public managers' behavior towards actors and organizations in their environment. The first mechanism is the transaction costs associated with initiating and maintaining network relations. Public managers must spend time and effort to initiate and maintain relations with external organizations. Some such organizations are relatively close to the agency, for example, because these organizations are a "natural" partner, or are located relatively close in a physical sense to the agency. Physical proximity is one of the best predictors for communication contacts (Allen 1984; Krackhardt 1994: 214; Rice and Aydin 1991). Proximity and transactions costs can also be viewed in terms of missions; organizations with different missions need to learn about each other to communicate effectively, and this need to learn adds additional transactions costs. Because networking 
relations with other organizations must be reciprocated, additional transaction costs arise (O’Toole \& Meier 2004b).

Transaction costs suggest that public managers are selective in their investment in relations with external organizations (Akkerman \& Torenvlied 2010). In a recent exploratory study, Akkerman and Torenvlied (2010) find indications that school directors maintain different types of ties with external organizations, related to goal-oriented investments by these directors. Not all links or potential links are alike; some can be expected to be useful for different reasons, and some are likely to be more valuable than others. Consequently, some such organizations will get more attention than others. A goal-oriented public manager will invest in contacts with those outside organizations which best serve the goals and interests of the core unit. We assume that some connection exists between the agency goals and the external organizations toward which public managers direct their networking activities. For example, the manager of an agency under tight budgetary constraints will prioritize network relations with other organizations that have a chance to yield financial support. The manager of an agency confronted with negative feedback from clients will be likely to prioritize network relations with interest groups and professional organizations in the field.

The mechanisms of transactions costs and goal-related investments in relations imply that public managers will make two choices: (a) deciding with which external organizations to develop and maintain a networking relation, and (b) determining how much effort to put into such a contact. They put effort into a networked contact by initiating a relationship and/or maintaining the relationship at a high frequency of interaction. The selectivity in the contacting behavior of managers and the variation in demands for support from external organizations imply that different dimensions of network activity must exist. This is our first hypothesis.

Hypothesis 1: Managerial networking has multiple dimensions, each related to a specific type of support to the agency that can be provided by external organizations.

External organizations differ in the amount of effort public managers need to put into maintaining relations, especially frequent relations. Some external actors or organizations, for example local politicians or local businesses, are more easily accessible for managers than are other such organizations - such as, for example, agencies of the national government. It will require more investment for public managers to maintain frequent relations with formal organizations (e.g., bureaucracies) than with informal organizations (e.g., client groups). 
Thus, organizations that yield the same type of support for public managers will differ with respect to the investment made by managers.

Hypothesis 2: External organizations that provide the same type of support are likely to differ with respect to the investment made by public managers to maintain (frequent) relations.

\section{Research context and data}

The context of managerial networking in the present study is U.S. education policy, in particular via school districts at the local level. These units are special-district governments with formal independence from other governmental institutions - they have their own taxing powers and elected officials. Districts vary in size (the number and enrollment of schools); and with respect to staff, experienced teachers, and school principals. Local education in the U.S. has developed into a significantly complex and interdependent setting. Schools are now venues for the delivery of a host of associated services or regulatory programs, from public health (vaccination programs, prevention of sexually transmitted diseases), to substance abuse, to the prevention and control of child abuse, to the achievement of nutritional objectives, to the reduction of adolescent violence, to civil rights, and to the improvement of life chances for disabled children. The "core" educational function has been surrounded by and insinuated into a panoply of other public objectives, and in turn a host of other organizations have become involved in the day-to-day functioning of school district activities.

School district superintendents are the chief administrators of school districts, and they are primarily responsible for managing this highly interdependent policy context. They typically report to an elected board but are charged with handling the day-to-day operations of their district, its performance, and both internal and external management. School superintendents have substantial discretion; they set goals for achieving school district policies, recruit and assign other administrators and teachers, and generally set the agenda on local education matters. Superintendents must also manage relationships with external actors who place political and technical demands on the district. These external actors and organizations play a role in both education and the numerous other functions (public health, safety, etc.) in which schools engage. Important ties include: (a) their school board, the elected body responsible for local policymaking, (b) relevant state-level and federal educational departments and politicians, who define regulations and provide opportunities for funding, (c) local business leaders, who often support locally enacted taxing decisions that are 
important for school district revenues, and (d) other school district superintendents, who provide peer advice and expertise, transfer innovations, and exchange experiences. The specifics regarding the survey data about managerial networking with these external parties were provided earlier.

The dependent variable in the illustrative analyses of school district performance-in which we compare the effects of network activity as multiple networking dimensions with the effects of one network activity factor-is the pass rate of Latino students on the Texas Assessment of Academic Skills (TAAS). This TAAS is a standardized, criterion-based test that all students in grade eleven must take, and pass, in order receive a regular diploma from the state of Texas. This measure is the percentage of Latino students in a district who passed all the (reading, writing, and math) sections of the TAAS (O'Toole \& Meier, 2004b).

\section{Cumulative scaling analysis}

To identify dimensions of superintendents' managerial networking we use a non-parametric "item-response" model for scaling analysis, the "Mokken model." The more commonly adopted scaling techniques of reliability analysis, factor analysis, and principal component analysis all assume that different items have the same mean and standard deviation. These techniques produce "common factors" or scales that are difficult to compare across different populations of subjects because factor and subjects' scores are interdependent. By contrast, "item response" theory separately models the subjects' scores on a "latent trait" and the item characteristics that measure the trait (Embretson \& Reise 2000: Van Schuur 2003: 143). The latent trait can be-for example — an attitude or ability. Well-known examples are students' proficiency in mathematics or reading ability. Other examples are voters' preferences for distinct policy alternatives. In the present study, the latent trait analyzed is the investment in networking relations by school system superintendents.

The core idea of item response theory is that each item is a separate test of the value of a respondent on the latent trait. Thus, subjects differ with respect to their ability, and items differ with respect to their "difficulty" for subjects, and both subjects and items are scaled on the same dimension. ${ }^{3}$ Difficulty is strictly defined as a methodological concept and refers to the likelihood that a subject is unable to "pass" the item test. The following classroom example provides a further clarification. Suppose that we wish to measure subjects' height.

\footnotetext{
${ }^{3}$ The relation between the level of subjects' trait $\theta_{\mathrm{s}}$ and the probability that a subject will give a positive response to item category $m(i)$ is described by the "item-characteristic curve" (ICC). Most parametric item-response models assume a logistic function, with additional scale-specific parameters.
} 
We can confront our subjects with a large set of gates that vary with respect to the headroom they offer to subjects. Each gate is an item. If a subject is able to pass through a gate without bumping her head, she will score a "one" on this item (gate). If, however, she happens to bump her head while passing through a gate, she will score a "zero" on that item (gate). From the response pattern of zeros and ones for subjects and gates we are able to deduce two rank orderings. The first is a rank ordering of subjects from tallest to shortest. The second is a rank ordering of gates from highest (least difficult to pass) to lowest (most difficult to pass). Both subjects and items are mapped in this order on the same one-dimensional scale. This scale is a "cumulative" scale, in the sense that a subject who passes an item with a particular difficulty is assumed to be able to pass all other items which are less difficult. In our example: if a subject is able to pass through a gate with a particular height, she has been able to pass through all gates that are higher (less difficult).

Although instructive, the example of measuring height by confronting subjects with gates of different heights simplifies the real complexities of measuring social constructs. For social constructs, subjects and items will be ordered with some level of error; that is, there will beat least theoretically_-subjects who pass a particular item, but fail to pass an item that is less difficult. Thus, errors are possible when ordering the frequencies of interaction of superintendents with different types of actors in the district's environment. To form a scale, errors should be randomly distributed, and are modeled using a probability function for subjects to "pass" an item of a given difficulty. ${ }^{4}$ For any scale, the observed errors are transformed into a "scale homogeneity" coefficient $H$, which is the inverse of the ratio between observed and expected errors. For individual items $i$ within a scale, an item homogeneity index $H_{\mathrm{i}}$ can be computed. As a rule of thumb, Mokken (1971) suggested the following interpretation of the strength of a scale-which appears to work quite well after decades of scaling analysis. For $H<0.30$ there is no response pattern that indicates the existence of a cumulative scale. For $0.30<H<0.40$ the scale is considered to be weak; for $0.40<H<0.50$ the scale is considered to be of intermediate strength, and for $H>0.50$ there exists a strong scale. For $H=1$, the scale is fully deterministic, and no errors occur.

In addition to random error, there is an additional element of complexity in the scaling procedure for our superintendents' contact frequencies with different types of external actors.

\footnotetext{
${ }^{4}$ These errors are called "Guttman errors" after Guttman, who developed a deterministic item-response model in a similar vein as the gates example: a subject with a value of the latent trait will pass all items that are less difficult than the item on this value, and will fail on the more difficult items. The non-parametric Mokken model assumes that the probability functions are non-decreasing. Parametric models, such as the Rasch model, assume logistic functions. These functions are not preferable for data with a relatively small number of items and subjects, as is the case for the superintendents' contact frequency data.
} 
These items are not dichotomous (with response categories: pass/fail), but instead polytomous (with multiple response categories varying from "never" to "daily" contacts). For such items, each response category is translated into a separate "item-step" (Molenaar 1997) and scaled accordingly. Consequently, categories are mixed across items when rank ordered at the onedimensional scale. For example, suppose that the items "contacts with state legislators" and "contacts with local business leaders" form a relatively homogeneous scale. Then, a possible rank ordering might indicate that that it is more difficult for superintendents to maintain monthly contact with state legislators than it is to maintain daily contact with local business leaders. Such a result would imply: (a) that the different categories of contacts with state legislators and local business leaders are indicators for the same one-dimensional latent trait of superintendents, for example their investment in political support, and (b) that contacts with state legislators require more investment or effort for superintendents than do contacts with local business leaders.

To test our hypotheses we use a cumulative scaling technique to identify differences in investment by managers. The difference between a common factor and a cumulative scale of two items is illustrated by looking at their bivariate distribution. If a common factor between two items exists, we expect the responses of superintendents to be linearly distributed. Figure 1(a) displays a hypothetical distribution of observations for a common factor, which is the area bounded by the dotted line. If the two items form a cumulative scale, we expect a different pattern to emerge. Suppose that, in figure 1(a), item $j$ is more difficult than item $i$ (for example because the type $i$ actors are less accessible and require more investments of superintendents). Then, superintendents who score high on item $i$ do not necessarily score high on item $j$. Depending on their personal or district characteristics, superintendents will vary in the extent to which they are able and/or willing to invest in combinations of contacts to these other actors. Thus, some superintendents (close to the item $i=\operatorname{item} j$ axis) invest as much time in maintaining contacts with both types of external actors. But it may also be that superintendents maintain more frequent contacts with type $i$ than with type $j$ actors. Their responses are distributed below the straight line. Figure 1(a) displays this hypothetical distribution of observations for a cumulative scale as the area bounded by the solid line. What do the data show? Figure 1(b) presents the empirical bivariate distribution of the items "contact with local business leaders" and "contact with state legislators" from the 2007 survey $(n=726)$. Indeed, figure 1(b) clearly shows indications that both items form a cumulative 
scale. ${ }^{5}$ Responses on both items are not strongly correlated $(\rho=0.32)$ but do form a weak to intermediate cumulative scale $(H=0.36)$.

\section{---Fig. 1 about here---}

\section{Results}

We apply a data-driven, exploratory design to obtain cumulative network activity scales from the superintendents' contact frequency data. ${ }^{6}$ The resulting cumulative scales have to satisfy three main criteria. The first, and most important, criterion is that each cumulative scale must be at least a weak scale $(H>0.30)$ and each item $i$ in the scale should have an item homogeneity index $H_{\mathrm{i}}>0.30$. These lower boundaries are standard for Mokken scale analysis (Molenaar et al. 2000; Jacoby 1994; 2000). Given the lower boundaries of $H=H \mathrm{i}>0.30$, we start with two items that form the strongest scale and subsequently add new items with the highest value of $H_{\mathrm{i}}$, until the lower boundary of $H$ is reached. ${ }^{7}$ We included the following items: "state legislators," "local business leaders," "parent groups," "teacher associations," “Texas Education Agency," and "Federal education officers".

We analyzed the superintendent data for each wave separately. Theoretically, this approach may result in different cumulative scales for separate waves. For example, a scale for one wave may contain a larger set of items than for a different wave. ${ }^{8}$ If hypothesis 1 holds, we should be able to construct (a) homogeneous, (b) consistent, and (c) clearly interpretable cumulative network activity scales for superintendents' contacts with external actors. From our analysis of these data, four network activity scales emerge which satisfy these criteria. ${ }^{9}$

\footnotetext{
${ }^{5}$ This triangle was also apparent in the data of Akkerman and Torenvlied (2010) on the external contacts of nine Dutch colleges for nursing studies.

${ }^{6}$ We used the MSP procedure (Mokken Scale analysis for Polytomous items) developed by Molenaar et al. (2000), implemented in STATA modules msp and loevH by Hardouin (2004).

7 This is the most commonly applied "bottom-up" procedure, although some authors use a "top-down" procedure, using one scale for all items and stepwise deleting all items with the lowest $H_{\mathrm{i}}$ until the lower boundary of $H$ is reached.

${ }^{8}$ Although this is not the case for the empirical application in the present paper, where we compare the 2002 and 2005 waves in the Texas School District dataset.

${ }^{9}$ In addition to obtaining a homogeneous scale, the procedure must produce a uniform rank ordering of the itemcategories $(m)$ from easiest to most difficult. A uniform rank ordering exists when the condition of "double monotonicity" (DM) holds: subjects are not allowed to have intersecting ICCs (Mokken 1971). Condition DM increases the validity of comparisons of scale scores of subjects on the same scale in different datasets (Van Schuur 2003). We applied a test that is based on the probability of a positive response to pairs of item-categories by subjects. A comparison is made of the positive responses across all item-categories by constructing an $m(i) \mathrm{x}$ $m(i)$ matrix, where the rows and columns are ordered from difficult to easy. This matrix is called the $\mathrm{P}^{1,1}$ matrix (Van Schuur 2000). If condition DM holds, the proportions in all cells of the $\mathrm{P}^{1,1}$ matrix must increase from left to right and from top to bottom. For each year and for each of the obtained network activity scales, we checked whether this assumption was violated by inspecting the $\mathrm{P}^{1,1}$ matrix. We did not observe strong violations of condition DM.
} 
Table 1 summarizes these four scales and presents the included items, the homogeneity indices, and the number of subjects in the analysis. With the exception of the coproduction scale for 2007 ( $H=0.29)$, all scales have a weak to moderate strength. ${ }^{10}$ Thus, hypothesis 1 holds: multiple dimensions of network management are thus documented, each directed towards a specific type of external organization. We label these dimensions: (1) political support; (2) bureaucratic coping; and (3) coproduction. Below we first report the different scales and discuss the substantive interpretation of each scale. Subsequently, we compare the results of an analysis of school performance with a one-dimensional factor with the results of the network dimensions provided by Mokken scale analysis

\section{---Table 1 about here---}

The first dimension of managerial networking that was found is a scale formed by the items "state legislators" and "local business leaders." We label this scale "political support." Superintendents need local political support to issue tax levies without public resistance, as well as support for bond referenda for capital construction. Similarly, they need legislative support to generate greater state funds for education. The second dimension of networking activity found is a scale containing the items "Texas Education Agency" and "Federal education officers." We label this scale "bureaucratic coping." Both state and federal bureaucracies are sources of regulations and jointly operate an accountability system for the school districts. These two items form one cumulative scale of weak-intermediate to intermediate strength, depending upon the year of measurement. No other items form a homogeneous scale with these two items, and none of these two items contribute with $H_{\mathrm{i}}>$ 0.30 to another scale. The third dimension of network management activity that we identified contains the items "teachers associations" and "parent groups." We label this scale “coproduction." Education is a coproduced good, and superintendents need both cooperation from teachers to implement their goals and active involvement by parents in the education of their children. These items form a weak to intermediate scale for both 2002 and 2005.

Overall, then, we find that the analysis does produce a series of dimensions of managerial networking that correspond to meaningful functions and scalable activities. Managerial networking, in short, is not some undifferentiated behavior but, when explored by this scaling

\footnotetext{
${ }^{10}$ A reliability analysis would reveal quite low Cronbach's $\alpha$ 's, which are: between 0.40 and 0.48 for the political support scale; between 0.39 and 0.50 for the bureaucratic coping scale; between 0.19 and 0.27 for the coproduction scale. Only for the contingency scale $\alpha=0.72$, which is acceptable given the fact that it includes only two items.
} 
technique, corresponds to distinguishable managerial responsibilities and patterns of relationships. Having provided a more substantive underpinning for the dimensions found in the superintendents' networking activities, we can further substantiate the results with a few additional analyses. We start by analyzing differences in "difficulty" between the items' categories. Each dimension of network activity is represented by a 12-point scale, because they are comprised of two six-point items. On these scales, item categories are ranked from "least difficult" to "most difficult"-that is, those receiving the least to the most investment made by superintendents.

\section{---Fig. 2 about here---}

Figure 2 shows the ranking of the six categories for all items in each of the three scales. We present here the results for the 2005 wave (the rank orderings for the other waves are similar). For political support, it is most "difficult" for superintendents to maintain frequent contacts with state legislators. Most superintendents who maintain daily contacts with local business leaders maintain only weekly contacts with state legislators. Although state legislators are the same type of external actor to superintendents, in terms of broad function, they appear to be much more "distant" to superintendents than are local business leaders. Superintendents devote most of their networking activity to maintaining contacts with local business leaders; and if this succeeds, or if they wish to invest more in this type of support, they turn to more frequent relations with state legislators.

For bureaucratic coping, the rank ordering of categories shows that the most "difficult" interaction frequencies are contacts more than once a week with federal education officers. It seems that maintaining daily contacts with the Texas Education Agency is a precondition for maintaining frequent contacts with federal officers. Again, the interpretation is that federal officers are more "distant" to superintendents than is the TEA, which provides a combination of support and monitoring to school districts. Federal officers perform a similar function as the TEA, but at a different (higher) level in the multilevel system of educational governance. For the coproduction scale, frequent contacts with teacher associations develop only when frequent contacts with parent groups are maintained. This seems logical, because school districts are likely to benefit more from intense relations with parent groups than with teacher organizations, and parent groups are probably more easily accessible than are teacher organizations. This is also logical because Texas does not have strong teachers' unions, and thus superintendents have significant discretion in this area. 
All in all, we conclude that the different types of actors within each dimension indeed differ in the extent to which (frequent) contacts are maintained with these actors. Thus, hypothesis 2 clearly holds, and the observed differences in the "difficulty" of maintaining contacts are well-justified through substantive argumentation.

\section{---Table 2 about here---}

As a further check for consistency, we examine correlations between the three different dimensions of networking activity. Because previous studies have consistently found only one factor accounting for the networking activity of superintendents, we checked the correlations across networking dimensions in Table 3 for the years 2002 and 2005. Clearly, the different dimensions of network activity are not highly associated. These correlations are generally low, between $\rho=0.20$ and $\rho=0.35$. The highest correlation exists between political support and contingency support $(\rho=0.48)$. The correlations with "other superintendents" are generally lower, except for "political support." Thus, we have further confidence that the four dimensions of network activity measure different aspects of support from the organization's environment.

\section{One factor versus multiple dimensional networking scales}

In this section we compare the results of analyses from a cumulative scale analysis of managerial networking with the results of a factor analysis. The goal of this analysis is to compare the results of a factor analysis with the dimensions derived from the cumulative scaling model. Interpretations are in terms of convergent validity (do the scales and factor capture the same patterns in managerial networking behavior) and discriminant validity (to what extent do the scales and factor capture different patterns in managerial networking behavior). Before doing so, we first report on the results of the factor analysis and how the factor scores are related to the different dimensions that result from the Mokken scale analysis.

We performed a factor analysis using the set of items which is included in all the three cumulative scales: State legislators and Local business leaders (political dimension); Texas Education Agency and Federal Education officers (bureaucratic coping dimension); Parent groups and Teacher associations (coproduction dimension). 
Table 3 shows that factor analyses replicate the results reported by Meier and O'Toole in their previous studies. For both years, only one factor with Eigenvalue $>1$ can be retrieved from the data. The Eigenvalue of a second factor is smaller than 0.10 for both years. All items load positively on the first factor. Table 4 further shows that the managerial networking factor is strongly correlated with all three dimensions, while the three dimensions are only weakly correlated with each other. Hence, although the factor captures common variance between the different dimensions, these dimensions capture different behavioral patterns of networking activity themselves.

\section{---Table 4 about here---}

Table 5 shows the results of the regression analyses for school performance including both the network dimension scores and the factor scores as explanatory variables. The factor has a significant positive effect on pass rates for Latino students. Hence, the general networking activity of superintendents positively affects school district performance for this subpopulation of students, controlling for various potentially confounding variables. This result replicates results reported by the previous studies of Meier and O'Toole.

However, the first dimension model, which includes the main effects of superintendents' network activity on each single dimension, shows that their networking activities in different "domains" of the school district environment have different effects. Coproduction does not affect the percentage of Latino students who pass the exams. Bureaucratic networking activity positively and significant affects these pass rates. Moreover, the effect of bureaucratic networking is more significant than the effect of the factor. Note that the explained variance does not change between the different models.

\section{---Table 5 about here---}

The final model in table 5 includes an interaction term of political and bureaucratic network dimensions. The inclusion of this interaction term illustrates how an analysis with separate dimension scores may produce more refined insights in the different and potentially contradictory networking effects that exist. This model shows a significant negative interaction effect between political and bureaucratic networking on the pass rates for Latino students. When we include this interaction effect, the main effects of political and 
bureaucratic networking turn significant and positive, meaning that school district superintendents who do not engage in (much) bureaucratic networking activity, perform much better the more active they are in political networking. The reverse also holds for superintendents who are not active in the political domains, but invest much in maintaining relations with bureaucratic actors. However, the districts of superintendents who invest much in both types of relationships tend to perform worse. This contradictory negative joint effect of political and bureaucratic networking most likely explains why we observe such a small effect of the factor score on pass rates for Latino students.

\section{Conclusion and discussion}

The most important message of the present paper is that managerial networking is not a onedimensional phenomenon, as is sometimes assumed in the literature on networks and managerial networking, but has several dimensions. The multidimensional nature of managerial networking activity logically follows from the assumption that managers have only limited time and resources available to maintain relations with other organizations. Transaction costs force managers to make conscious investments in networking relations that are conducive to the agency's goals. When managers indeed are selective in their networking activities, different dimensions of managerial networking must emerge. We do indeed find evidence for the existence of multiple dimensions of networking activity in a large- $n$, fourwave dataset on the frequency of managerial networking contacts maintained by Texas school district superintendents.

The three dimensions of networking activity emerge from these data, thus showing distinctive activities aiming at: (a) political support, (b) bureaucratic coping, and (c) coproduction,. These dimensions are consistent and stable across years, and well-interpretable for the context in which school district superintendents operate. External organizations differ in the extent to which they receive more investments from superintendents. Thus, the present paper illustrates how a scaling approach - one that is virtually absent in public management research: -- can be use to explicate behaviorally distinct patterns that map onto managerially distinct functions. The technique is cumulative scaling, based on item-response theory. Almost all other public management studies use reliability analysis or factor designs, despite indications that cumulative scaling techniques are sometimes more appropriate.

The dimensions of networking activity developed here, furthermore, bear similarities to some of the conceptual discussions in the research literature regarding the functions that external networking efforts by managers might involve. One can note, for instance, the four 
different kinds of activities sketched by McGuire (2002), who argued conceptually for the likely value of distinguishing these different forms of managerial networking behavior. In addition, the Mokken-scale patterns elicited in the present analysis have parallels to several of those developed recently from managerial data gathered in a different country [reference deleted for review]. It would appear, therefore, that the networking dimensions developed here may have importance beyond the field of public education in Texas, and beyond this particular data set.

Our results also shed new light on extant theories of managerial networking. Current approaches make elaborate distinctions between the functions of network relations (exchange of information and resources, building trust, coordination of activities), but pay relatively little attention to the types of networking contacts needed to build such relations. Thus, the present study provides a clear direction for a further specification of explanatory models of network management-by focusing on the deliberate choices managers make to initiate and maintain contacts with specific types of external organizations. Such a model can provide a much stronger theoretical underpinning to the correlates between managerial networking and performance than has been done in earlier work, which has mainly focused on general networking activity and/or generic network structures. Paired with empirical analyses of the dimensions of managerial networking, the explanatory model can be contextualized for specific agencies, policy sectors, or institutional settings. Thus, the multiple dimensions model of managerial networking can relate the constrained, goal-oriented networking behavior of public managers to specific indicators for the performance of their agency.

To provide deeper and more nuanced explanations for variation in agency performance, at least two steps need to be taken in future research. The first is to identify different types of managers, based on their networking activity on the separate dimensions. Some managers, for example, may be active in political networking but less so in their relations with bureaucratic actors. Other managers might instead focus their networking activity towards organizations that are important for coproduction. The determinants of differences in managers' networking strategies are important to link agency goals to networking activity. A second line of analysis would be to test empirically how strongly specific networking approaches by managers may affect various indicators of agency performance.

It would seem, therefore, that some important lines of additional empirical work are opened up by the type of analysis conducted here. In addition, the present analysis should be replicated in different institutional contexts-for example in different countries and also, data permitting, in other fields of policy and management aside from public education. The 
current investigation provides strong evidence that distinct scales of managerial networking can represent different important functions as managers ply their trade outward in the interdependent environments of their own organizations. Identifying such patterns in other empirical settings would be a significant contribution to knowledge.

\section{References}

Agranoff, Robert, and Michael McGuire. 2003. Big questions in public network management research. Journal of Public Administration Research and Theory 13(3): 295-326.

Akkerman, Agnes and René Torenvlied. 2010. Managing the Agency Environment: Effects of Network Ambition on Agency Performance. Public Management Review 13(4): forthcoming.

Akkerman, Agnes, René Torenvlied, Jelmer Schalk and Jim Allen. 2009. When do networks help perform better and why? Paper presented at the XIII Annual Conference of the International Research Society for Public Management (panel 15 on public management and organizational performance organized by the Public Management Research Association), Copenhagen, April 5-8.

Allen, Thomas J. 1984. Managing the flow of technology: Technology transfer and the dissemination of technological information within the r\&d organization. Cambridge, MA: MIT Press.

Bardach, Eugene. 1998. Getting agencies to work together: The practice and theory of managerial craftsmanship. Washington DC: Brookings Institution Press.

Brass, Daniel J., Joseph Galaskiewicz, Henrich R. Greve, and Wenpin Tsai. 2004. Taking stock of networks and organizations: A multilevel perspective. Academy of Management Journal 47(6): 795-817.

Collins, Christopher J., and Kevin D. Clark. 2003. Strategic human resources practices and top management team social networks. Acadamy of Management Journal 46(6): 740-752.

Embretson, Susan E., and Steven P. Reise. 2000. Item response theory for psychologists. Mahwah, NJ: Lawrence Erlbaum Publishers.

Hanf, Kenneth, Benny Hjern, and David O. Porter. 1978. Local networks of manpower training in the Federal Republic of Germany and Sweden. In: Kenneth Hanf, and Fritz Scharpf (eds.), Interorganizational policymaking: Limits to coordination and central control (pp. 303-341). Beverly Hills, CA: Sage.

Hardoin, Jean Benoit. 2004. MSP / LoevH stata modules. Statistical software components. S439402. Chestnut Hill, MA: Boston College Department of Economics. 
Hite, Julie M., Ellen J. Williams, and Steven C. Baugh. 2005. Multiple networks of public school administrators: An analysis of network content and structure. International Journal of Leadership in Education 8(2): 91-122.

Jacoby, William G. 1994. Public attitudes toward government spending. American Journal of Political Science 38(2): 336-361.

Jacoby, William G. 2000. Issue framing and public opinion on government spending. American Journal of Political Science 44(4): 750-767.

Kraatz, Matthew S. 1998. Learning by association? Interorganizational networks and adaptation to environmental change. The Academy of Management Journal 41(6): 621-643.

Krackhardt, David. 1994. Constraints on the interactive organization as an ideal type. In: Charles Heckscher, and Anne Donnellan (eds.), The post-bureaucratic organization (pp. 211-222). Beverly Hills, CA: Sage.

Leana, Carrie L., and Frits K. Pil. 2006. Social capital and organizational performance: Evidence from urban public schools. Organization Science 17(3): 353-366.

McGuire, Michael. 2002. Managing networks: Propositions on what managers do and why they do it. Public Administration Review 62 (5): 599-609.

Meier, Kenneth J., and Laurence J. O’Toole Jr. 2001. Managerial strategies and behavior in networks: A model with evidence from U.S. public education. Journal of Public Administration Research and Theory 11 (3): 271-293.

Meier, Kenneth J. and Laurence J. O’Toole, Jr. 2003. Public management and educational performance: The impact of managerial networking. Public Administration Review 63 (6): 689-699.

Meier, Kenneth J., and Laurence J. O’Toole, Jr. 2008. Management theory and Occam's razor: How public organizations buffer the environment. Administration and Society 39 (8): 931-58.

Mizruchi, Mark S. 1994. Recent achievements and current controversies. Acta Sociologica 37(4): 329-343.

Mokken, Robert J. 1971. A theory and procedure of scale analysis. With applications in political research. The Hague: Mouton.

Molenaar, Ivo W., Robert J. Mokken, Wijbrandt H. van Schuur, and Klaas Sijtsma (2000). MSP version 5. Groningen: Progamma.

O’Toole, Laurence J., Jr. 1997. Implementing public innovations in network settings. Administration and Society 29(2): 115-138. 
O’Toole, Laurence J., Jr., and Kenneth J. Meier. 1999. Modeling the impact of public management: Implications of structural context. Journal of Public Administration Research and Theory 9(4): 505-526.

O'Toole, Laurence J., Jr., and Kenneth J. Meier. 2004a. Public Management in intergovernmental networks: Matching structural networks and managerial networking. Journal of Public Administration Research and Theory 14(3): 271-293.

O’Toole, Laurence J., Jr., and Kenneth J. Meier. 2004b. Desperately seeking Selznick: Cooptation and the dark side of public management in networks. Public Administration Review 64(6): 681-693.

W. Powell, Walter, and Laurel Smith-Doerr. 1994. Networks and economic life. In: Neil J. Smelser, and Richard Swedberg (eds.), The handbook of economic sociology (pp. 368402). Princeton: Princeton University Press.

Provan, Keith G., and H. Brinton Milward. 1995. A preliminary theory of interorganizational network effectiveness: A comparative study of four community mental health systems. Administrative Science Quarterly 40(1): 1-33.

Provan, Keith G., and Patrick Kenis. 2008. Modes of network governance: Structure, management, and effectiveness. Journal of Public Administration Research and Theory 18(2): 229-252.

Rethemeyer, R. Karl, and Deneen M. Hatmaker. 2007. Network management reconsidered: An inquiry into management of network structures in public sector service provision. Journal of Public Administration Research and Theory 17(1): 1-30.

Rice, Ronald E., and Carolyn Aydin. 1991. Attitudes toward new organizational technology: Network proximity as a mechanism for social information processing. Administrative Science Quarterly 36(2): 219-244.

Schalk, Jelmer, René Torenvlied, and Jim Allen. 2010. Network embeddedness and organizational performance. The strength of strong ties in Dutch higher education. Journal of Public Administration Research and Theory. (Published online JPART advance access 31 July 2009).

Schneider, Saundra K., William G. Jacoby, and Jerrell D. Coggburn. 1997. The structure of bureaucratic decisions in the American States. Public Administration Review 57(3): 240249.

Stuart, Toby E., and Joel M. Podolny. 1999. Positional consequences of strategic alliances in the semiconductor industry. Research in the Sociology of Organizations 16:161-182. 
Tsai, Wenpin. 2001. Knowledge transfer in intraorganizational networks: Effects of network position and absorptive capacity on business unit innovation and performance. Academy of Management Journal 44(5): 996-1004.

Van Schuur, Wijbrandt H. 2003. 'Mokken scale Analysis: Between the Guttman Scale and Parametric Item Response Theory'. Political Analysis 11(2): 139-163.

Zaheer, Akbar, Bill McEvily, and Vincenzo Perrone 1998. Does trust matter? Exploring the effects of interorganizational and interpersonal trust on performance. Organization Science 9(2): 141-159.

Zahn, G. Lawrence. 1991. Face-to-face communication in an office setting: The effects of position proximity and exposure. Communication Research 18(6): 737-754. 
Table 1

Homogeneity of four network activity Mokken scales (Loevinger $H$ coefficients; $n$ in parentheses)

1. Political support

State legislators

Local business leaders

0.38

0.30

(643)

(687)

2. Bureaucratic coping

Texas education Agency

0.31

0.39

Federal Education officers

(639)

(709)

3. Coproduction

Parent groups

0.35

0.36

Teacher associations

(640)

(698)

Non-scalable: other superintendents

Note. For all scales: $p<.001$. 
Table 2

Pearson correlations between the four network activity scales.

\begin{tabular}{lcccccccc}
\hline & \multicolumn{3}{c}{$2002(n=623)$} & & \multicolumn{3}{c}{$2005(n=648)$} \\
\cline { 2 - 5 } \cline { 6 - 8 } & 2 & 3 & 4 & & 2 & 3 & 4 \\
\hline 1. Political support & 0.25 & 0.34 & 0.22 & & 0.29 & 0.30 & 0.43 \\
2. Bureaucratic support & 1.00 & 0.26 & 0.23 & & 1.00 & 0.36 & 0.25 \\
3. Coproduction & & 1.00 & 0.09 & & & 1.00 & 0.10 \\
4. Other superintendents & & & 1.00 & & & 1.00 \\
5. Contingency support & & & & & & & \\
\hline
\end{tabular}

Table 3

Results of the factor analysis

\begin{tabular}{|c|c|c|c|c|}
\hline & \multirow{2}{*}{\multicolumn{2}{|c|}{$\begin{array}{l}2002(\mathrm{n}=597) \\
\mathrm{F} 1, \text { Eigen value }=1.217\end{array}$}} & \multirow{2}{*}{\multicolumn{2}{|c|}{$\begin{array}{l}2005(\mathrm{n}=599) \\
\mathrm{F}, \text { Eigen value }=1.385\end{array}$}} \\
\hline & & & & \\
\hline & Factor loadings & Uniqueness & Factor loadings & Uniqueness \\
\hline State legislators & 0.5071 & 0.7429 & 0.4684 & 0.7585 \\
\hline Local business leaders & 0.4053 & 0.8264 & 0.4317 & 0.8091 \\
\hline TEA & 0.3743 & 0.8337 & 0.4248 & 0.7905 \\
\hline Federal ed. officers & 0.4530 & 0.7796 & 0.5300 & 0.7162 \\
\hline Parent groups & 0.4625 & 0.7768 & 0.5215 & 0.7056 \\
\hline Teachers Associations & 0.4861 & 0.7591 & 0.4963 & 0.7301 \\
\hline
\end{tabular}

\begin{tabular}{l}
$\begin{array}{l}\text { Table } 4 \\
\text { Correlation between the managerial networking factor and the three dimensions for } 2002(\mathrm{n}=597) \\
\text { and for 2005 }(\mathrm{n}=599) \text {. }\end{array}$ \\
\hline
\end{tabular}


Table 5

OLS Regression of pass rates for Latino students (unstandardized coefficients; robust standard errors between parentheses).

Network variables

Factor networking

0.86*

(0.47)

Political networking

0.18

$1.83 * *$

Bureaucratic networking

$(0.27)$

(0.92)

$0.47 *$

$2.61 * *$

(0.24)

(1.20)

Coproduction

$-0.03$

0.03

(0.28)

$(0.27)$

Political*Bureaucratic

\section{Control variables}

Year dummy

$-27.23 * * *$

(0.76)

$-27.14 * * *$

(0.77)

$-27.16 * * *$

$\%$ Afro-Am. students

$-0.06$

(0.04)

$-0.06$

(0.76)

\% Latino students

0.01

(0.04)

$-0.06$

0.01

(0.04)

$\%$ Low income students

(0.03)

(0.03)

0.01

$-0.20 * * *$

(0.03)

$-0.20 * * *$

(0.03)

Total expenditures

0.00

(0.04)

$-0.20 * * *$

(0.04)

(0.02)

0.00

0.00

Student to teacher ratio

0.09

(0.02)

$(0.02)$

$\begin{array}{lll} & & (0.27) \\ \text { Instructional expenditures } & \text { per } & 0.00\end{array}$

pupil

(0.00)

0.10

0.09

(0.27)

(0.26)

Constant

$87.99 * * *$

(5.90)

0.00

0.00

(0.00)

(0.00)

\begin{tabular}{ll} 
& $(5.90)$ \\
$\mathrm{N}$ & 1127 \\
$\mathrm{R}^{2}$ & 0.64 \\
\hline$* \mathrm{p}<.1 ; * * \mathrm{p}<.05 ; * * * \mathrm{p}<.005$ &
\end{tabular}

$84.45^{* * *}$

(5.90)

$73.61 * * *$

1127

(8.23)

0.64

1127

0.64 
Figure 1

Distributions of subjects' responses on two items.

C. Expected bivariate distribution of subjects for two items with a common factor (dotted line) and two items that form a cumulative scale (solid line).

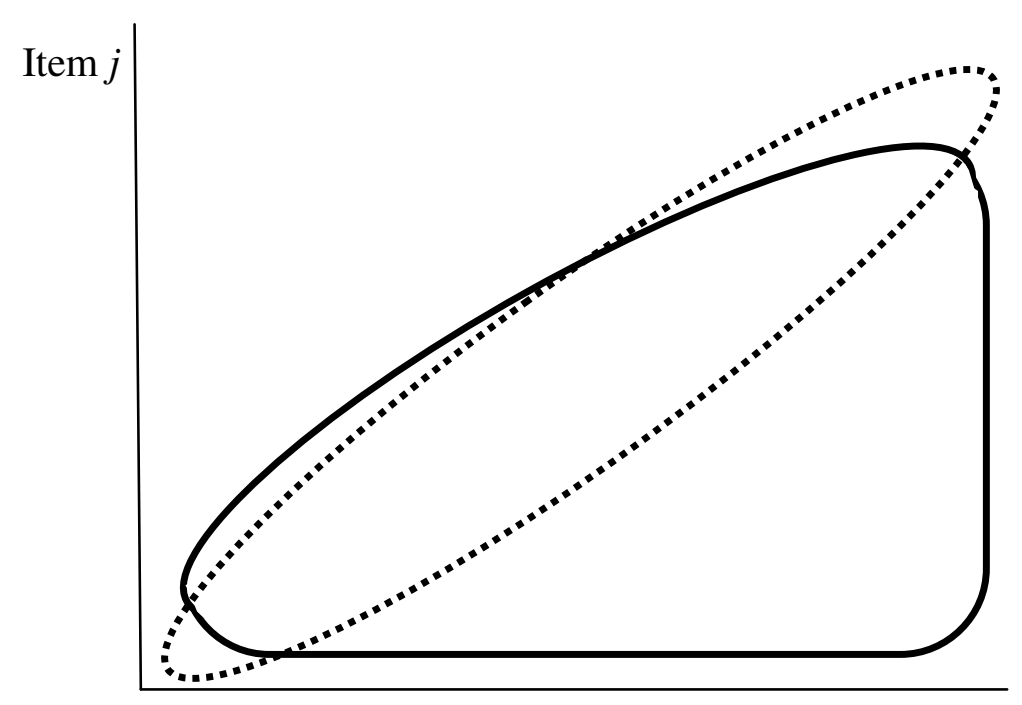

Item $i$
A. Empirical bivariate distribution of items "contact with local business leaders" and "contact with

state legislators" for the 2007 survey $(n=724 ; \rho=$ 0.32 ).

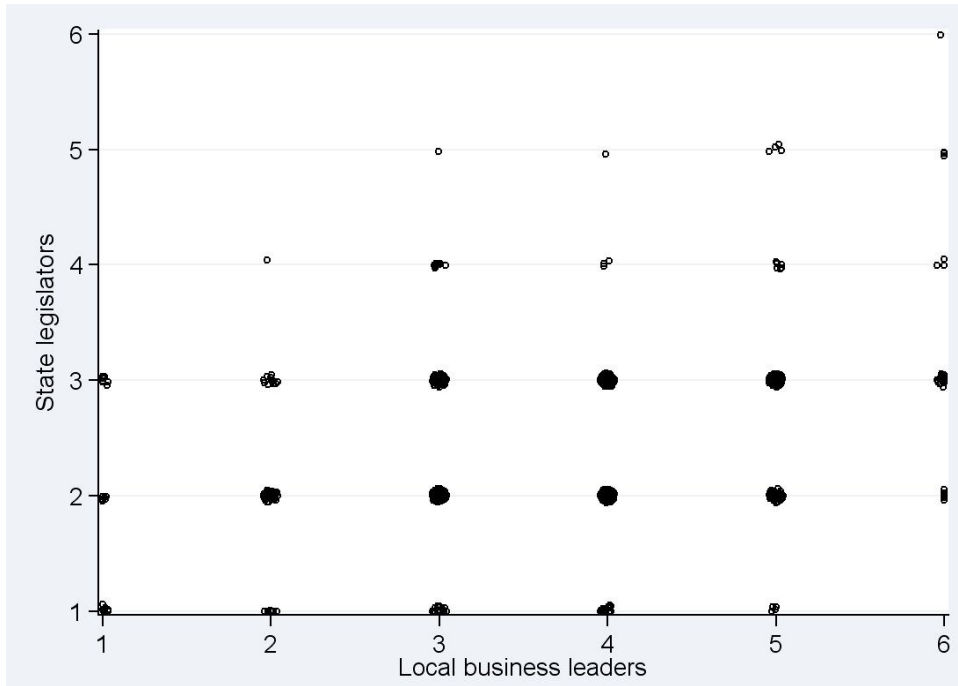

Note. $1=$ never; $2=$ yearly; $3=$ monthly; $4=$ =eekly; $5=$ more than once a week; $6=$ daily. 


\section{Figure 2}

Item categories ranking in difficulty for the four network activity scales in 2005

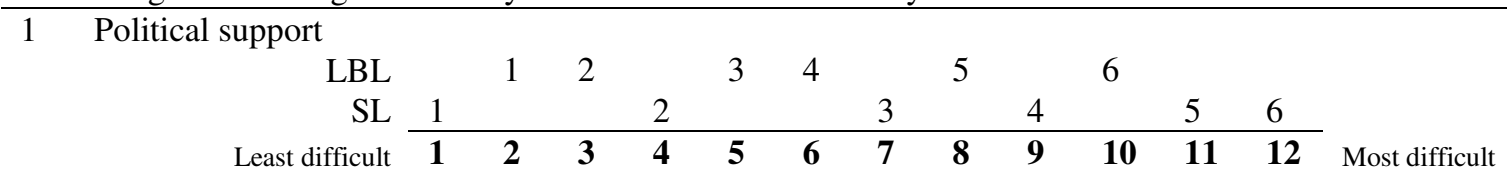

2 Bureaucratic coping

\begin{tabular}{rlllllllllllll} 
TEA & & 1 & 2 & 3 & & 4 & & 5 & & 6 & & \\
FEO & 1 & & & & 2 & & 3 & & 4 & & 5 & 6 \\
\cline { 2 - 12 } Least difficult & $\mathbf{1}$ & $\mathbf{2}$ & $\mathbf{3}$ & $\mathbf{4}$ & $\mathbf{5}$ & $\mathbf{6}$ & $\mathbf{7}$ & $\mathbf{8}$ & $\mathbf{9}$ & $\mathbf{1 0}$ & $\mathbf{1 1}$ & $\mathbf{1 2}$ & Most difficult
\end{tabular}

3 Coproduction

\begin{tabular}{|c|c|c|c|c|c|c|c|c|c|c|c|c|}
\hline $\begin{array}{l}\mathrm{PG} \\
\mathrm{TA}\end{array}$ & 1 & 2 & 3 & & & 4 & 5 & 4 & 5 & 6 & 6 & \\
\hline 1 & 2 & 3 & 4 & 5 & 6 & 7 & 8 & 9 & 10 & 11 & 12 & Most difficult \\
\hline
\end{tabular}

Note. LBL=Local business leaders; SL=State legislators; 1=never; 2=yearly; 3=monthly; 4=weekly; $5=$ more than once a week; $6=$ daily. 